\title{
Improved Efficiency and Voltage Gain Conversion Ratio using Inductor Model based modified Dickson Charge Pump
}

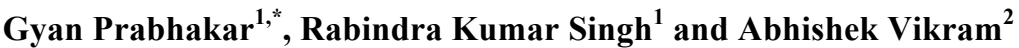 \\ ${ }^{1}$ Dept. of Electronics Eng. Kamla Nehru Institute of Technology, Sultanpur, Dr. APJ Abdul Kalam Tech. Univ. Lucknow, U.P., India. \\ ${ }^{2}$ Dept. of Electrical Eng. Motilal Nehru National Institute of Technology, Allahabad, UP, India.
}

Received 17 March 2018; Accepted 2 August 2018

\begin{abstract}
This paper proposes an inductor-based DC-DC conversion technique using the 5-stage Dickson charge pump that achieves efficiency up to $96 \%$. The converter that the Dickson charge pump is built on is a novel series inductor and parallel capacitive construction, that is profitable for energy harvesting applications. In this paper, we have shown the use of an inductor in five stage Dickson charge pump to generate an output voltage of $8.76 \mathrm{~V}$ at $20 \Omega$ resistive load with a 50 $\mathrm{MHz}$ external frequency. Least drop in voltage is at output capacitor that is used as an energy storage element. In the experiment, the integrated charge-up converter is based on LC tank features. This unique simulation study is done in the $\mathrm{T}$-Spice $0.18 \mu \mathrm{m}$ CMOS process using an input voltage of $1.8 \mathrm{~V}$, using high $\mathrm{Vt}$ and low oxide thickness Tox for reducing threshold voltage drop in latter stages.
\end{abstract}

Keywords: Inductor-capacitive Dickson charge pump, conventional Dickson charge pump, Power efficiency, $\mathrm{R}_{\text {on }} \mathrm{MOS}$ resistance, NonOver lapping Clock generator, Nonvolatile memories, integrated LC tank model

\section{Introduction}

The world of electronics is becoming dominated by mobile applications such as laptop computers and cellular phones. In such applications, reducing power consumption has increasingly become an important requirement for integrated circuits [1]. But with parallel circuit operation, higher throughput request builds pressure on clock rate and active current consumption. Charge pumps are a way of switching connection to control the connection of voltages to the capacitor [2]. At present, low power supply computer, SRAM, Input/output systems and several additional applications are widely used. Depending on these technologies, embedded systems often include high density flash drives on the same chip. Regardless of power fashions, Non-Volatile Memories, as well as Electrical Erasable PROMs, require maximum voltages $\sim 4 \mathrm{~V}-7 \mathrm{~V}$ to enable hot electron injection and tunneling during writing and erasing actions. [3]. Capacitive load pumps based on the Dickson design structure [1] are widely used to increase the input onchip voltage. The key constraints of such a methodology are: 1) the boosting phase 1 and 2 in each stage required in low voltage processing technologies that lead to the deterioration of energy efficiency and 2) the large area on chip needed by them $[4,5]$.

This paper modified Dickson charge pump using LC tank based integrated architecture charge pump. After conducting the literature survey, we found that some architectural products have been produced for improving power efficiency. In previous papers on this topic, we have observed that circuit complexity increases to improve power efficiency. Efficiency has been shown to improve

*E-mail address: gyanprabhakar@gmail.com

ISSN: 1791-2377 @ 2018 Eastern Macedonia and Thrace Institute of Technology. All rights reserved. doi:10.25103/jestr.114.01 substantially, but it requires balancing a lot of parameters, that is a complex task - such as output power, delay, rise time etc. On the contrary, when the efficiency increases to an extent then the output voltage decreases due to the complex architecture. It is essential to have a better charge pump, regulating the balance current to the final output stage with the load [6].

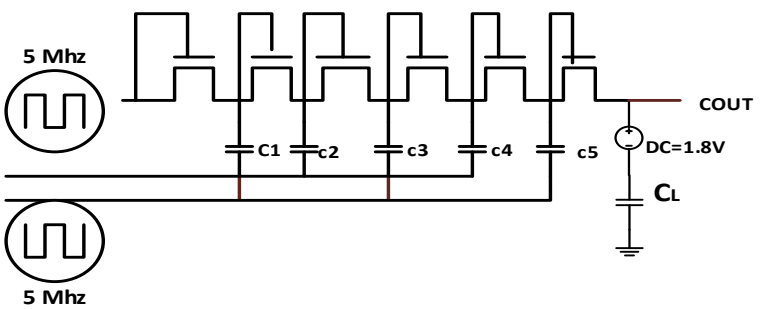

Fig. 1. The Dickson Charge Pump

In this paper, Inductor has been used to impress efficiency because the inductor produces a large current that is needed for the charge pump to work well. The related inclusive boost-up circuit behavior and efficiency analysis are presented in Section 2. In Section 3, the flow of model of integrated LC tank used in circuit simulations is introduced. In section 4 , two phase Non-overlapping Clocking scheme Timing behavior circuit block it is important circuit block for charge pump circuit operation. Finally, in Section 5, measurement results at various load resistances are provided, and conclusions are discussed in Section 6.

\section{Dickson Charge Pump Circuit Behavior and outcome Problems with Efficiency Analysis}

The traditional charge pump invented by J.F. Dickson [7] is based on diode-connected NMOS transistor structure where 
the capacitive energy storage step circuit provided roughly a final voltage: $\mathrm{V}_{\text {out }}=(\mathrm{N}+1) \times\left(\mathrm{V}_{\mathrm{dd}}-\mathrm{V}_{\mathrm{t}}\right)$, where $\mathrm{N}$ is number of stages, $\mathrm{V}_{\mathrm{dd}}$ is the input supply voltage, and $\mathrm{V}_{\mathrm{t}}$ is the threshold voltage of the MOS transistor. It is to be noted that, as the voltage is increased by boost pump, body effect increases due to threshold voltage MOS transistors and each stage drops voltage by $\mathrm{V}_{\mathrm{dd}}-\mathrm{V}_{\mathrm{T}}$, thereby the power efficiency is reduced at the final stage. While the threshold voltage cannot be scaled as much the scaling of the supply voltage, the effect of the increase of the threshold voltage on the lowering of the output voltage becomes significant in the scaled $\mathrm{V}_{\mathrm{dd}}$. There after several attempts have been made to re-design the structure for decreasing the threshold voltage $[8,9]$. Actually, efficiency parameter depends on the current at each stage, which regulates the output level in each stage and leads to full charge transfer. A boost converter charge pump DC/DC depends on switching, instead of passtransistor. The power efficiency $\eta$ at the output is a measure of performance [8].

$\eta=\frac{I_{L} \times V_{\text {out }}}{I_{\text {power }} \times V_{d d}} \times 100=\frac{V_{\text {out }}}{(n+1) \times\left(V_{d d}-V_{t}\right)}$

Where $\mathrm{I}_{\mathrm{L}}$ is the output current; $\mathrm{V}_{\text {out is }}$ the output voltage; $\mathrm{I}_{\text {power }}$ is the current delivered through $\mathrm{V}_{\mathrm{dd}}$ to charge pump. $V_{d d}-V_{t}$ is the voltage gain per stage with threshold voltage drop $V_{t}[9]$. The current $\mathrm{I}_{\text {power }}$ can be written as

$$
I_{\text {power }}=(n+1) \times I_{\text {Load }}+I_{p}
$$

Where $I_{p}$ current in parasitic capacitors, required to charge and discharge the capacitors.

$$
I_{p}=n \times C_{p} \times f \times V_{d d}
$$

$\mathrm{n}$ is the number of stage and $C_{p}$ is the parasitic capacitance. $C_{p}$ is relative to the boost capacitance itself by a factor $\alpha$ [10].

$I_{p}=n \times \alpha \times C \times V_{d d} \times f$

Thus, charge pump power efficiency can be written as

$$
\eta=\frac{\frac{V_{\text {out }}}{V_{d d}}}{(N+1) \alpha \times\left(\frac{N^{2}}{N+1}-\frac{V_{\text {out }}}{V_{d d}}\right)} \times 100
$$

The $\alpha$ is a technology-dependent parameter and ranges from 0.1 (for poly-poly capacitors) up to 0.3 like metal-metal capacitors) $[11,12]$.

2.1 Behavior of Inductor Model and MOS $R_{0 n}$ Resistance The main parameter in the design of charge pump is the current that should be delivered at regulation level. In this proposed charge pump the inductor behaves as a current source at $\mathrm{t}=\infty$ when the current starts flowing in the circuit, and the capacitor behaves as a voltage source when current is flowing in the circuit at $\mathrm{t}=0^{+}$as Fig 2 and Fig 3.

\section{Inductor based modified Dickson, charge pump model}

The NMOS transistor used in the charge pump behaves like a control switch, as the voltage from the inductor is higher than input voltage and the output current is much lower than the input. When the switch is ON and OFF very fast, the inductor magnetic field never collapses. Therefore, when the switch 2 is opened again, this causes a higher voltage on the inductor as it adds to the magnetic flux. In this circuit the inductor has a critical role, when the current is increasing, then it prevents it from decreasing and when the current is decreasing, it prevents it from increasing.

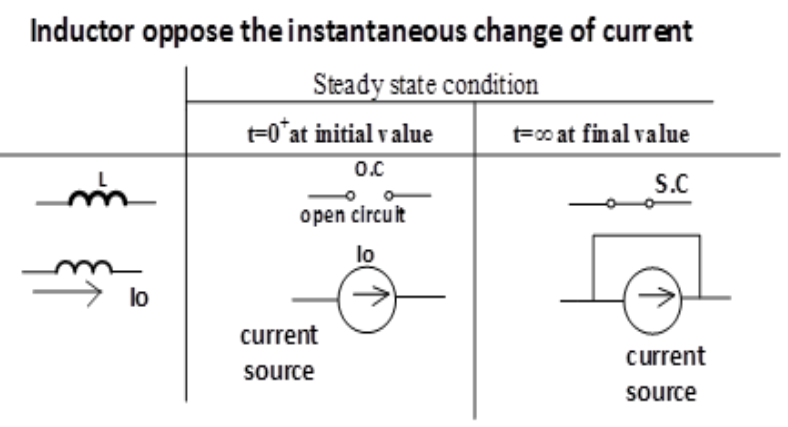

Fig 2. Inductor Behavior at $\mathrm{t}=0^{+}$and $\mathrm{t}=\infty$

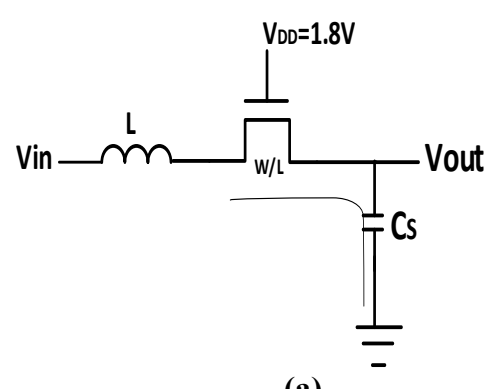

(a)

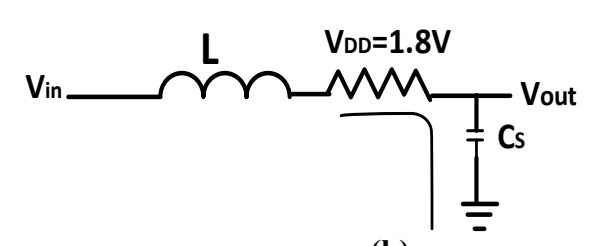

(b)

Fig 3. a) Inductor based Switch and b) inductive-resistive model.

$$
\begin{aligned}
& \mathrm{R}_{\mathrm{n}}=\frac{V_{D D}}{\frac{K_{P}}{2} * \frac{W}{L}\left(V_{D D}-V_{T H N}\right)^{2}} \\
& \mathrm{Req}=\frac{L}{\mu \operatorname{Cox} *\left(V_{D D}-V_{T H N}\right)^{2} * W}
\end{aligned}
$$

There have been other attempts to design better charge pumps through structural modifications [13, 14]. The schematic of the basic operation of the first stage of the inductor-based Dickson charge pump is shown in figure (3). It is limited by the threshold voltages drop in the Dickson charge pump [15]. Alternatively, dc/dc converters based on inductive mechanism is widely used in power electronics, and in recent times, they have been integrated into CMOS standard processes [16]. The inductor techniques using diode generic circuit is shown in figure (4) by (Massimiliano Zucchelli and Luigi Colalongo, 2016).

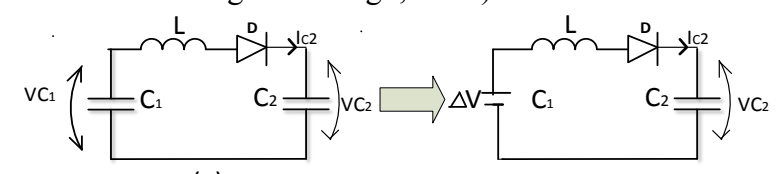

(a)

(b)

Fig. 4. Schematic of the basic operation of the first stage of the inductive-based Dickson charge pump. 


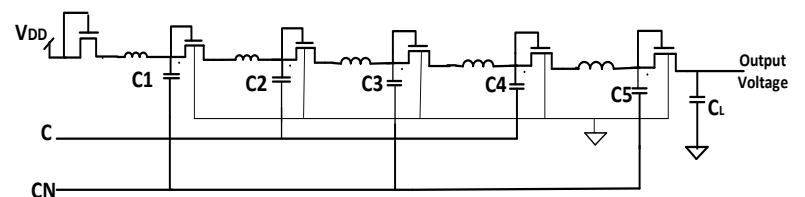

Fig. 5. Proposed Model of Inductor based Dickson Charge Pump.

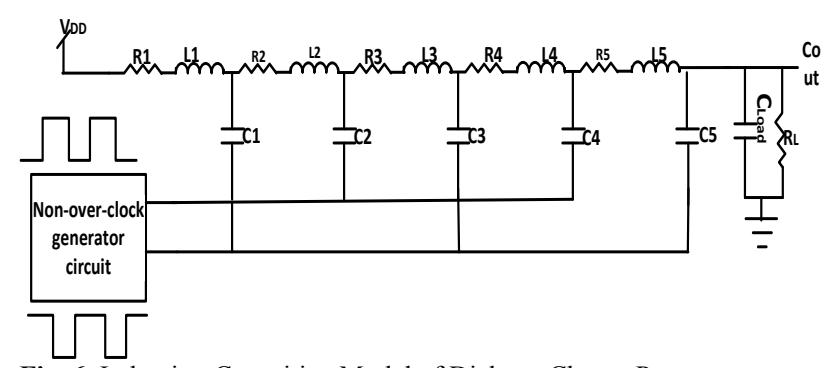

Fig. 6. Inductive-Capacitive Model of Dickson Charge Pump

The major limits of a completely integrated LC tank converter approach are the efficiency at low input voltage. The LC tank converters produce sufficient current to deliver to a clock signal which maintains the current level at each node [17]. The circuit diagram of the proposed inductorbased boost converter is shown in figure (5). The Charge Pump circuit receives a clock signal from the nonoverlapping clock circuit. The value of $\mathrm{L}$ and $\mathrm{C}$ sets the desired frequency; the current can be adjusted through the value of inductor current. In this fashion, all parameters can be controlled to enhance the efficiency and reduce the ripple voltage [18].

$f=\frac{1}{\sqrt{L C}}$

The 5- Stage Modified inductor charge pump is a combination of the capacitors $\mathrm{C}_{1}-\mathrm{C}_{5}$ and inductor $\mathrm{L}_{1}-\mathrm{L}_{2}$ and $\mathrm{C}_{\text {out }}$ is output capacitors as shown in Fig (5). The modified LC tank converter can be well matched with low power in inductive-capacitive structural design and can be fabricated in standard low-voltage CMOS process [19].

As shown in Figure 3, a model LC tank DC converter is formed by a switch, an inductor, and a diode-attached MOS. The charge pumps up to boost approximately five times that can generate output voltage $8.5 \mathrm{~V}$ from input $1.8 \mathrm{~V}$ [20]. The energy of inductor used in charge pump is Inductor energy

$E=\frac{1}{2} L i^{2}$

\section{Non-overlapping Clocking scheme Timing behavior}

Non-overlapping clocking scheme timing behavior is key circuit block for any charge pump circuit. The Charge Pump is never work without clock operation so it is required two phase non-over lapping clock circuit operation design through seven stage CMOS based ring oscillator circuit. The Ring Oscillator is not able to generate non-over lapping clock, therefore associated with using non-overlapping circuit using cross coupled CMOS based NAND gates. The overlapping clocking schemes consumes too much power which increases the dynamic power losses during switching operation. Non-overlapping circuit is reducing dynamic power operation during circuit switching operation. The ring oscillator with non-overlapping circuit output waveform shown in Fig (7). The Non-over clock circuit behavior shown in Fig (8).
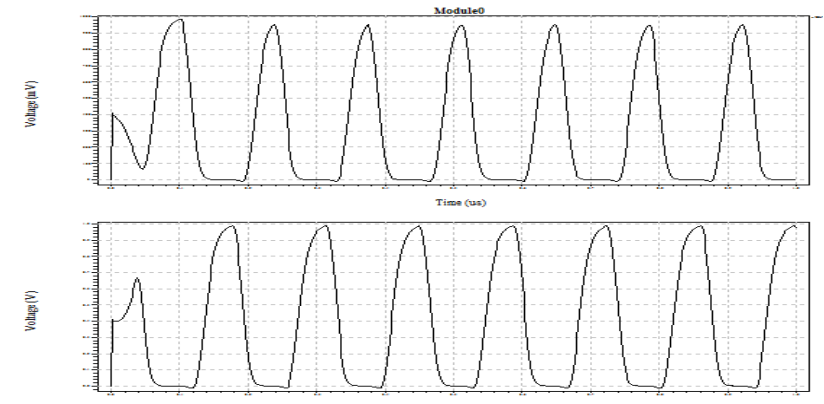

Fig. 7. Clock output voltage through Ring oscillator.
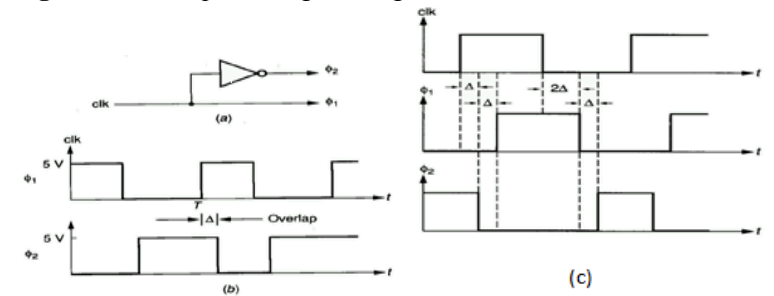

(c)

Fig. 8. (a) Generate two-phase clock using inverter, (b) Showing clock overlapping behavior (c) Ideal clock behavior of Non-over lapping circuit

\section{Clocked DFF (Timing Circuit).}

The timing circuit block in master slave fashion shown in Fig (9). It is providing smooth square wave and reduce the power loss during energy storage phase.
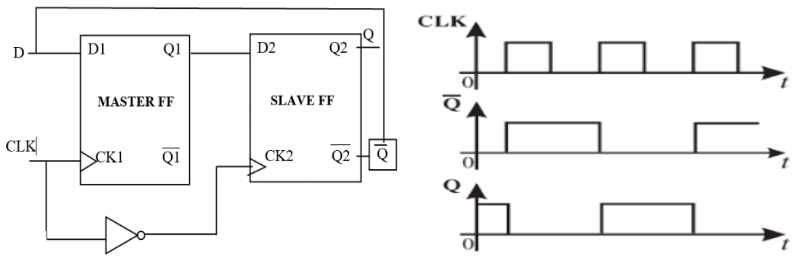

Fig. 9. Block of Master-Slave DFF

In Figure (9) is shown a clocked CMOS based DFF in master-slave fashion based on this circuit. It has a better pulse converter that is designed to reduce the power loss during the energy storage phase. When the NMOS control switch is ON the current flows from the input voltage source through the inductor, and the energy is stored in the inductor. The DFF produces a timing circuit for the proposed inductor-based Dickson charge pump. The main clock generator in the first phase is CMOS based ring oscillator through an odd number of stages. The seven-stage $(n=7)$ ring inverter has been selected as a substitution. The $50 \%$ to $75 \%$ of the duty cycle is produced in the second stage [21]. Thus, a digital D-flip-flop (a master-slave type) and a NAND gate provide two output signals ( $Q$ and $\mathrm{Q}$ ) with $1 / 2$ frequency. The NAND gate varies between CLK and ${ }^{-} \mathrm{Q}$, with $75 \%$ duty cycle signals [22-24].

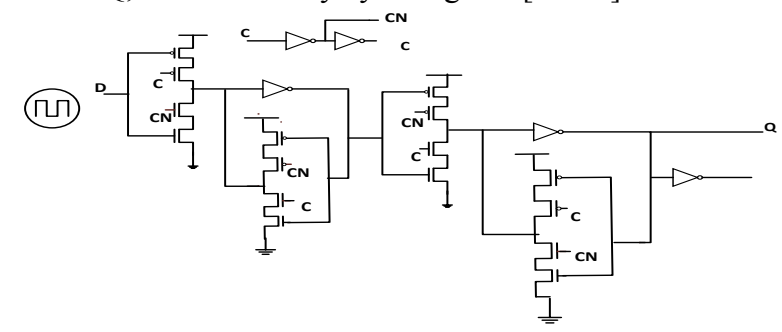

Fig. 9. Clocked CMOS based D-Flip Flop Master-Slave Fashion 


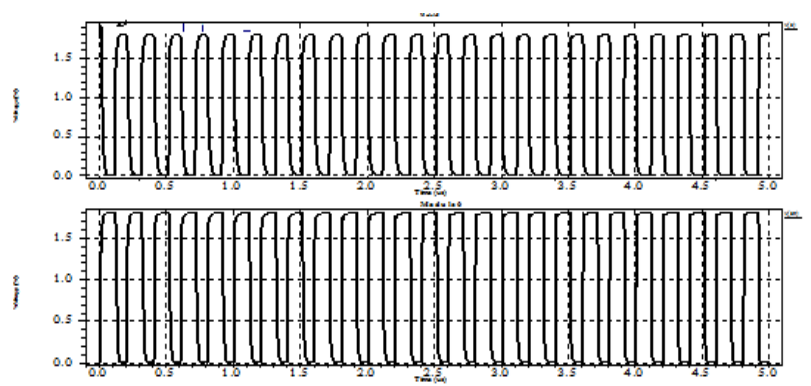

Fig. 10. Clock out voltage through clocked CMOS based D-Flip Flop Master-Slave DFF

\section{Simulation Result Inductor and without inductor}

The proposed inductor charge pump is simulated by using the T-Spice software in $0.18 \mu \mathrm{m}$ CMOS technology. The voltage gain output per stage of the five-stage charge pump using an inductor and without inductor based on conventional charge pump circuit is shown in figure 5 . It is observed that as the MOS resistance value is varied between $20 \Omega$ and $100 \Omega$, it has an impact on the output voltage at $\mathrm{L}=100 \mu \mathrm{H}$ and Supply voltage $1.8 \mathrm{~V}$. The efficiency is largely improvised at different values of pumping MOS capacitors $6 \mathrm{pF}-20 \mathrm{pF}$ with various load output resistance. In this paper Table 1 shows the Technology and Tools specification of parameters that have been used, Table 2 shows the values of parameters that are used during simulation.

Table 1. Tools \& Technology Specification -Transient Analysis-Design Summary

\begin{tabular}{c|l}
\hline Schematic & Tanner schematic composer \\
\hline Simulation & Transient Analysis \\
Technology used & $180 \mathrm{~nm}$ NMOS Level 49 Technology \\
& (MOSIS) \\
$\mathrm{V}_{\mathrm{t}}$ & High $\mathrm{V}_{\mathrm{t}} 0.49$ \\
Minimum Channel & $180 \mathrm{~nm}$ CMOS \\
Length $\mathrm{L}_{\text {min }}$ & $4.6 \mathrm{~nm}(\mathrm{NMOS}) \&(\mathrm{PMOS})$ \\
$\mathrm{T}_{\mathrm{ox}}$ & $292 \mu \mathrm{A} / \mathrm{V}^{2}$ \\
$\mathrm{~K}_{\mathrm{n}} \mu^{*} \mathrm{C}_{\mathrm{ox}}$ & $1455 \mu \mathrm{A} / \mathrm{V}^{2}$ \\
$\mathrm{~K}_{\mathrm{p}} \mu^{*} \mathrm{C}_{\mathrm{ox}}$ & $1.8 \mathrm{~V}$ \\
${\text { Power Supply } \mathrm{V}_{\mathrm{DD}}}_{\mathrm{C}_{\mathrm{ox}}}$ & $8.46 \mathrm{fF} /(\mu \mathrm{m})^{2}$ \\
\hline
\end{tabular}

Table 2. Charge pump specifications

\begin{tabular}{l|c|c}
\hline \multicolumn{1}{c|}{ Specification } & Name & Value \\
\hline Steady output Voltage $(\mathrm{V})$ & $\mathrm{V}_{\text {OUT }}$ & $6.5 \mathrm{~V}$ \\
Pumping Capacitor $(\mathrm{pF})$ & $\mathrm{C}_{1}$ to $\mathrm{C}_{5}$ & $6 \mathrm{pF}, 20 \mathrm{pF}$ \\
Output Load capacitance in $(\mathrm{pF})$ & $\mathrm{C}_{\mathrm{L}}$ & $1 \mathrm{pF} .10 \mathrm{pF}$ \\
Output Load Resistance in $(\mathrm{k} \Omega)$ & $\mathrm{R}_{\mathrm{L}} / \mathrm{R}_{\text {out }}$ & $250,500,750,1000$ \\
Output voltage ramp time $(\mu \mathrm{s})$ & $\mathrm{T}_{\mathrm{RAMP}}$ & $10 \mu \mathrm{s}$ \\
Pump power supply voltage $(\mathrm{V})$ & $\mathrm{V}_{\mathrm{DD}}$ & $1.8 \mathrm{~V}$ \\
Average pump current & $\mathrm{I}_{\mathrm{PUMP}}$ & $6 \mu \mathrm{A}$ \\
consumption $(\mu \mathrm{A})$ & & \\
Rise/fall time $(\mathrm{ns})$ & $\mathrm{t}_{\text {rise }}$ and $\mathrm{t}_{\text {fall }}$ & $2.60 \mathrm{~ns} / 1.23 \mathrm{~ns}$ \\
\hline
\end{tabular}

In Figure 11, output voltage $\mathrm{V}_{\text {out }}$ variation with MOS $\mathrm{R}_{\text {on }}$ resistance is shown. In this graph, we observe that by increasing the value of inductor to five times, the value of the output increases to 1 volt. Thus, there is an effect of inductor value on the output voltage. In this graph, $\mathrm{R}_{\mathrm{on}}$ is the drain to source resistance that is actually decided by $\mathrm{W}$ and L of the MOS transistor, and both are technology dependent parameters. The MOS $R_{\text {on }}$ resistance value is derived from $\mathrm{W} / \mathrm{L}$ ratio.

The low value of MOS resistance can transfer the maximum charge and receive maximum voltage thereby reducing power consumption. As a result, the efficiency increases. Because of the low value of $R_{\text {on }}$ resistance, the maximum current is delivered to the final stage, which improves the voltage gain and efficiency.

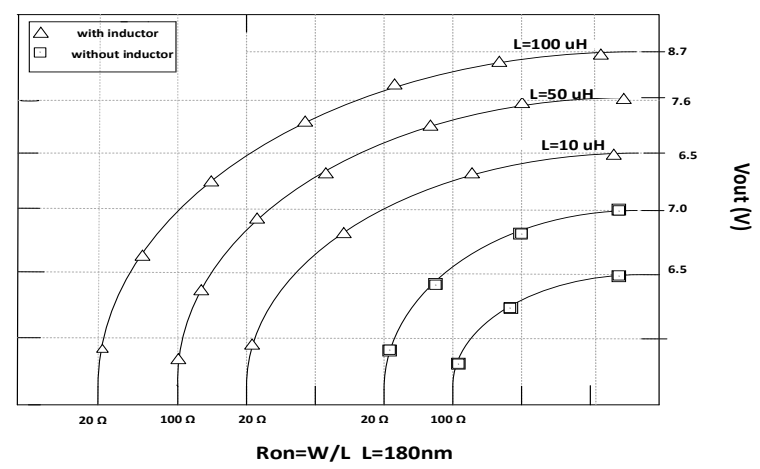

Fig. 11. T- Spice simulation comparison results of output voltage variation vs. efficiency vs MOS Ron resistance for conventional charge pump without inductor and proposed using inductor Dickson charge pump

Case-1 Inductor (L) and MOS resistance (Ron) play an important role in this simulation result. When $R_{\text {on }}=20 \Omega$ and $\mathrm{L}=10 \mu \mathrm{H}$ then output voltage reaches $6.5 \mathrm{~V}$. While when $\mathrm{R}_{\text {on }}$ $=20 \Omega$ and $\mathrm{L}=100 \mu \mathrm{H}$ then output voltage reaches to maximum $8.7 \mathrm{~V}$. When $\mathrm{L}=50 \mu \mathrm{H}$ and $\mathrm{R}_{\text {on }}=100 \Omega$, Vout $=7.6$ $\mathrm{V}$. The inductor and the MOS resistance are the key parameters of inductor based Dickson charge pump design. It proves to be helpful in increasing the voltage gain and power efficiency.

Case-2 Without inductor when $\mathrm{R}_{\text {on }}=20 \Omega$, output reaches 7.0 V. Then on further increasing the value of MOS resistance, the output voltage decreases significantly.

Table 3. Output Voltage measured with and without Inductor

\begin{tabular}{l|c|c|c}
\hline & $\begin{array}{c}\text { Inductor } \\
\text { (L) in } \boldsymbol{\mu H}\end{array}$ & $\begin{array}{l}\text { MOS Resistance } \\
\text { (Ron) in } \boldsymbol{\Omega}\end{array}$ & $\begin{array}{l}\text { Output Voltage } \\
\text { (Vout) in V }\end{array}$ \\
\hline With & 10 & 20 & 6.5 \\
Inductor & 50 & 100 & 7.6 \\
& 100 & 20 & 8.7 \\
\hline Without & -- & 20 & 7.0 \\
Inductor & -- & 100 & 6.5 \\
\hline
\end{tabular}

Using inductor value $\mathrm{L}=100 \mu \mathrm{H}$ - figures 12 and 13 show simulation result of efficiency analysis of 5 stage and 3 stage Dickson charge pump circuit under the various output load resistance $\left(\mathrm{R}_{\mathrm{L}}\right) 250 \mathrm{k} \Omega-1000 \mathrm{k} \Omega$, pumping capacitors $6 \mathrm{pF}$ and Figure 13 at $20 \mathrm{pF}$. The efficiency achieved is up to 96 $\%$ on load resistance value of $250 \mathrm{k} \Omega$, but efficiency is decreased up to $55 \%$ on load resistance value $1000 \mathrm{k} \Omega$ using 5 stage charge pump. When using 3 stage charge pump at the same load value, the efficiency is observed going up to $60 \%$ and maintains above $50 \%$ at $1000 \mathrm{k} \Omega$ load resistance. Similar explanation follows for the figure 13 .

The figures 14 and 15 show simulation result of the relation between output voltage and efficiency with capacitors value $6 \mathrm{pF}$ at $\mathrm{N}=5$ stage, and $\mathrm{N}=3$ stage charge pump circuit under the various output load resistance $\left(\mathrm{R}_{\mathrm{L}}\right)$ $250 \mathrm{k} \Omega-1000 \mathrm{k} \Omega$. It is observed that the efficiency increases as the output voltage is decreases and power increases. It means that when we want to achieve more efficiency for better charge pump work, then output voltage has to be compromised of 5 stages charge pump to produce the best efficiency in the range $96 \%$ to $55 \%$. For $\mathrm{N}=3$ stage charge pump efficiency ranges between $60 \%$ to $50 \%$. 


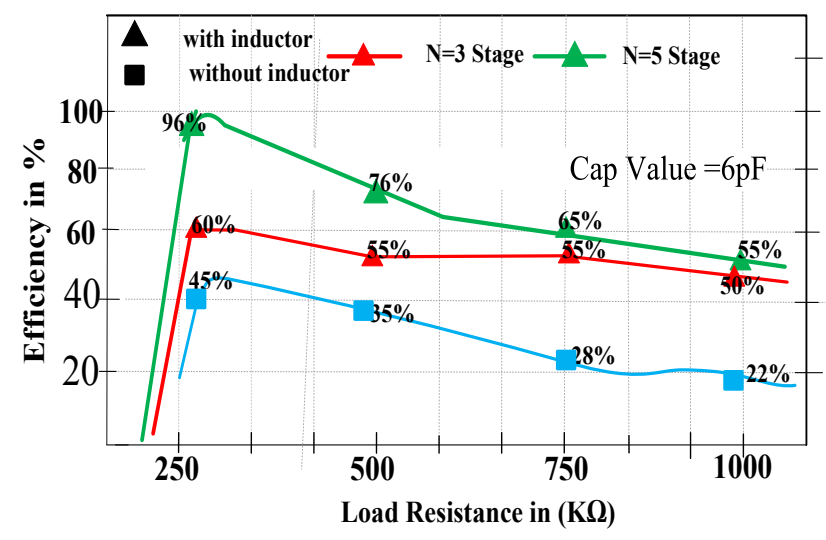

Fig. 12 Efficiency vs Load resistance at $6 \mathrm{pF}$

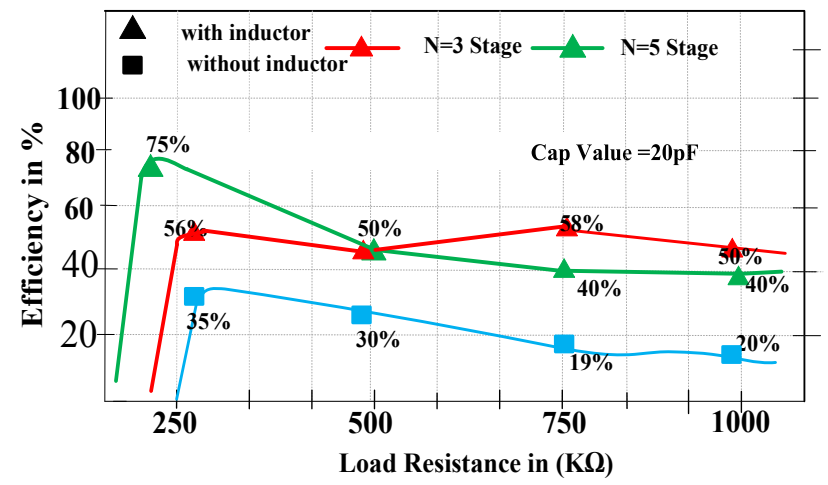

Fig. 13 Efficiency vs Load resistance at $20 \mathrm{pF}$

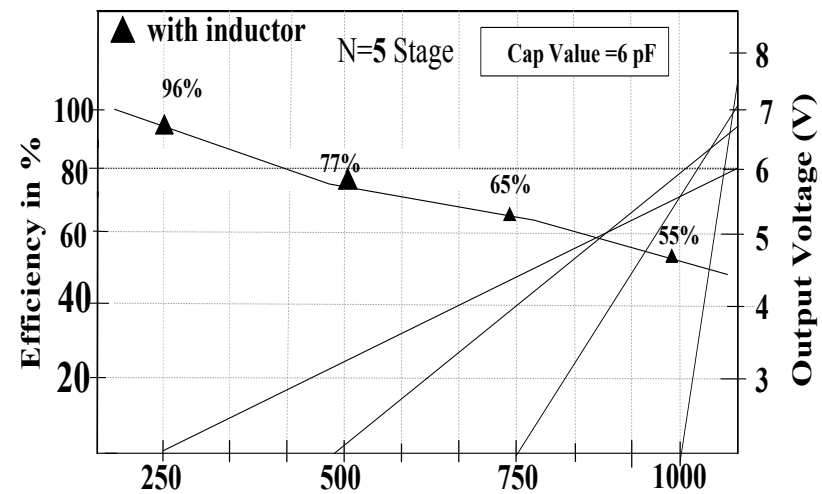

Fig. 14 Relation between Efficiency and output voltage at output load resistance at $6 \mathrm{pf}, \mathrm{N}=5$ Stage.

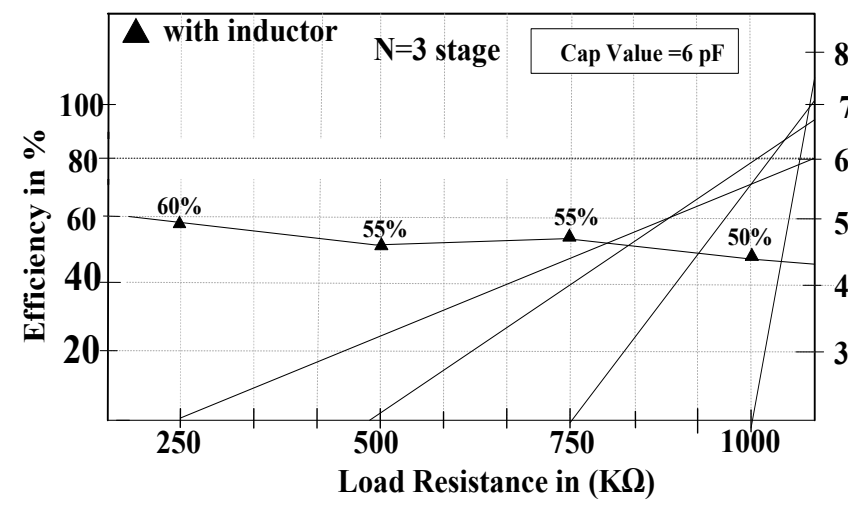

Fig. 15 Relation between Efficiency and output voltage at output load resistance at $6 \mathrm{pf}, \mathrm{N}=3$ Stage
The figures 16 and 17 show simulation results for $20 \mathrm{pf}$ capacitor value and follows similar description as for figures 14 and 15 , for the relation between output voltage and efficiency.

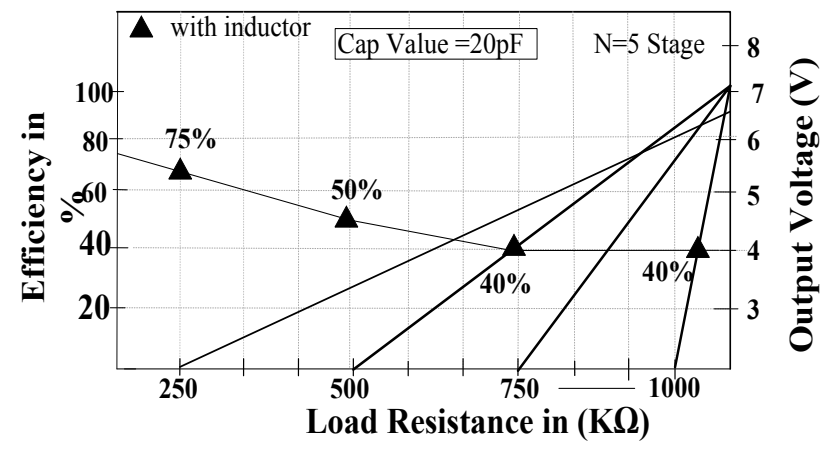

Fig. 16 Relation between Efficiency and output voltage at output load resistance at $20 \mathrm{pf}$.

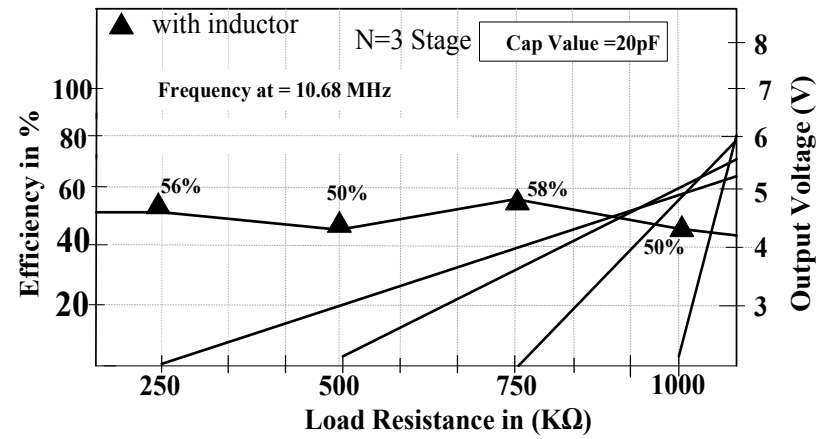

Fig. 17 Relation between Efficiency and output voltage, N=5 Stage at output load resistance at $20 \mathrm{pf}, \mathrm{N}=3$ Stage.

The figures 18 and 19 show simulation result of output power with capacitor value $6 \mathrm{pF}$ and $20 \mathrm{pF}$ of 5 stage and 3 stage charge pump circuit under the different output load resistance $\left(\mathrm{R}_{\mathrm{L}}\right) 250 \mathrm{k} \Omega$ to $1000 \mathrm{k} \Omega$. It is observed that the output power decreases with increasing load resistance.

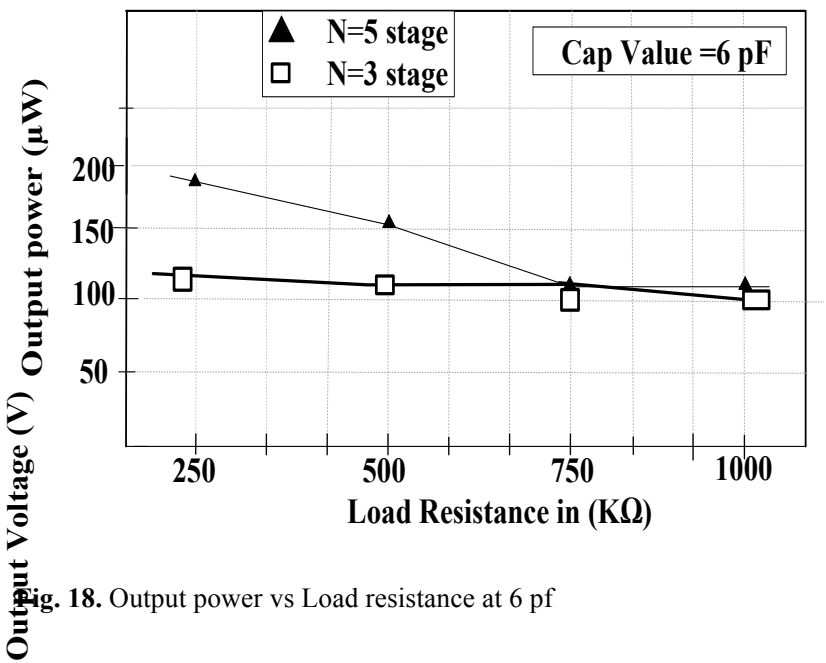

The figures 20 and 21 show simulation result of the output current with capacitor values $6 \mathrm{pF}$, and $20 \mathrm{pF}$ for 5 stage and 3 stage charge pump circuit under the different output load resistance $\left(\mathrm{R}_{\mathrm{L}}\right) 250 \mathrm{k} \Omega$ to $1000 \mathrm{k} \Omega$. The output current is observed to decrease with higher resistance values. 


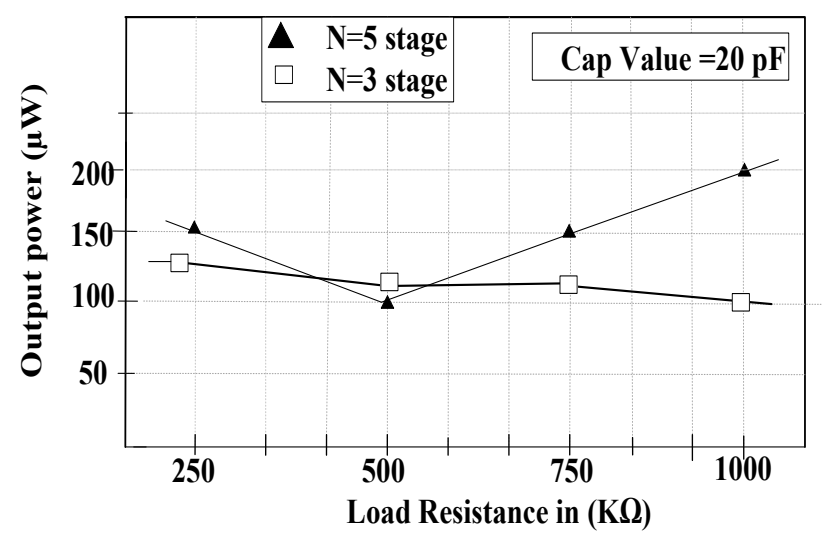

Fig. 19. Output power vs Load resistance at $20 \mathrm{pf}$

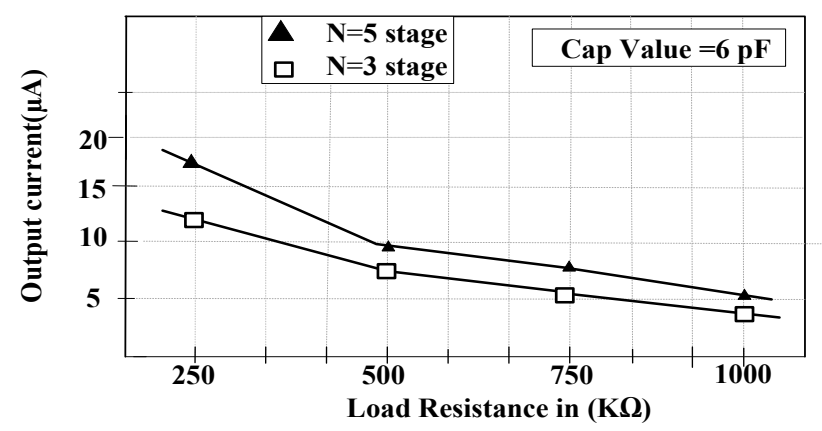

Fig. 20. Output current vs Load resistance at $6 \mathrm{pf}$

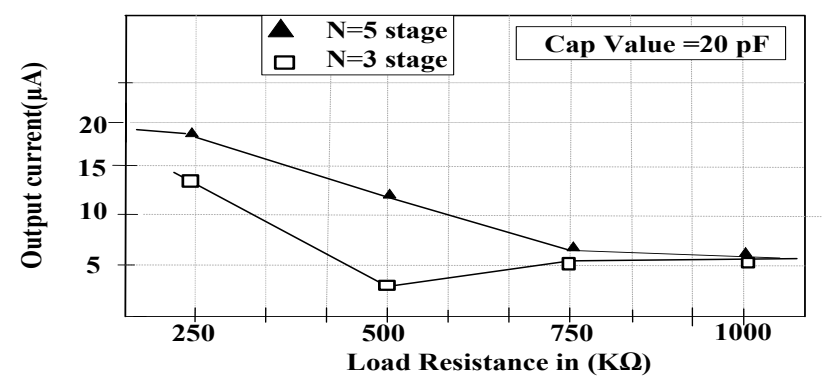

Fig. 21. Output current vs Load resistance at $20 \mathrm{pf}$

Figure 22 shows simulation result of Output voltage vs $\mathrm{N}=3$ and $\mathrm{N}=5$ stage of charge pump circuit at 6 pf. It clear shows an increase in output voltage value with increasing number of stages.

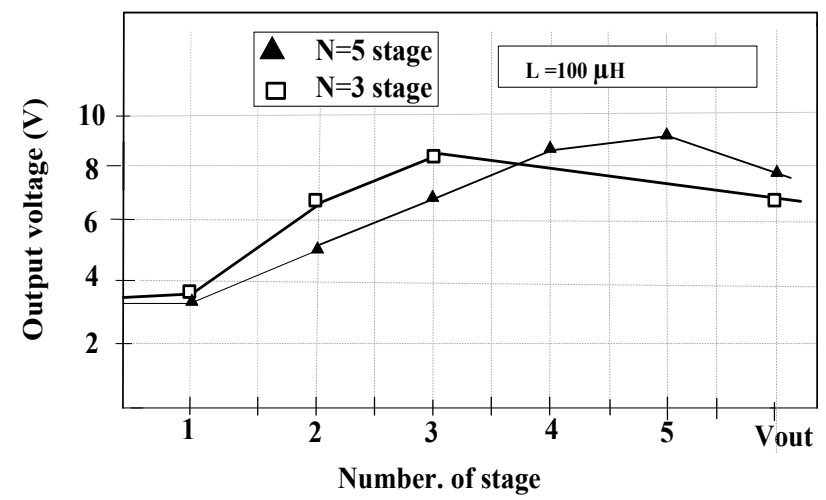

Fig. 22. Output voltage vs No. of stage at $6 \mathrm{pf}$
Table 4. Simulation Result Analysis - Performance

Summary at $6 \mathrm{pF}$.

\begin{tabular}{|c|c|c|c|c|c|c|c|c|}
\hline \multicolumn{5}{|c|}{ Result at, $\mathrm{L}=100 \mu \mathrm{H}$ at frequency $32.49 \mathrm{MHz}$} & \multicolumn{4}{|c|}{$\begin{array}{l}\text { Result at, } \mathrm{L}=100 \mu \mathrm{H} \text { at } \\
\text { frequency } 19.49 \mathrm{MHz}\end{array}$} \\
\hline \multicolumn{5}{|c|}{$\mathrm{C} 1$ to $\mathrm{C} 5=6 \mathrm{pF} \mathrm{N}=5$} & \multicolumn{4}{|c|}{$\mathrm{C} 1$ to $\mathrm{C} 3=6 \mathrm{pF} \mathrm{N}=3$} \\
\hline $\begin{array}{l}\text { Load output } \\
\text { resistance } \\
\mathrm{R}_{\mathrm{L}}(\mathrm{K} \Omega)\end{array}$ & 250 & 500 & 750 & 1000 & 250 & 500 & 750 & 1000 \\
\hline $\begin{array}{l}\text { output voltage } \\
\text { (V) }\end{array}$ & 6 & 6.8 & 7.1 & 7.5 & 5.0 & 5.5 & 5.9 & 6.0 \\
\hline $\begin{array}{l}\text { Efficiency } \Pi \\
(\%)\end{array}$ & 96 & 77 & 65 & 55 & 60 & 55 & 55 & 50 \\
\hline $\begin{array}{l}\text { output power } \\
(\mu \mathrm{w})\end{array}$ & 193 & 154 & 110 & 110 & 118 & 110 & 110 & 100 \\
\hline $\begin{array}{l}\text { output current } \\
(\mu \mathrm{A})\end{array}$ & 18 & 10 & 7.0 & 5.5 & 13 & 7.1 & 6 & 4.5 \\
\hline
\end{tabular}

Table 5. Simulation Result Analysis- Performance Summary at $20 \mathrm{pF}$.

\begin{tabular}{|c|c|c|c|c|c|c|c|c|}
\hline \multicolumn{5}{|c|}{$\begin{array}{l}\text { Result at, } \mathrm{L}=100 \mu \mathrm{H} \text { at frequency } 17.75 \\
\mathrm{MHz}\end{array}$} & \multicolumn{4}{|c|}{$\begin{array}{l}\text { Result at, } \mathrm{L}=100 \mu \mathrm{H} \text { at } \\
\text { frequency } 10.68 \mathrm{MHz}\end{array}$} \\
\hline \multicolumn{5}{|c|}{ Pumping Capacitor $\mathrm{C}_{1}$ to $\mathrm{C}_{5}=20 \mathrm{pF} \mathrm{N}=5$} & \multicolumn{4}{|c|}{$\begin{array}{l}\text { Pumping Capacitor } \mathrm{C}_{1} \text { to } \\
\mathrm{C}_{3}=20 \mathrm{pF}, \mathrm{N}=3\end{array}$} \\
\hline $\begin{array}{l}\text { Load output } \\
\text { resistance } \\
\mathrm{R}_{\mathrm{L}}(\mathrm{K} \Omega)\end{array}$ & 250 & 500 & 750 & 1000 & 250 & 500 & 750 & 1000 \\
\hline $\begin{array}{l}\text { output } \\
\text { voltage (V) }\end{array}$ & 6.5 & 7.0 & 7.1 & 7.1 & 5.2 & 5.5 & 5.8 & 5.9 \\
\hline $\begin{array}{l}\text { Efficiency } \prod \\
(\%)\end{array}$ & 75 & 50 & 40 & 40 & 56 & 50 & 58 & 50 \\
\hline $\begin{array}{l}\text { output power } \\
(\mu \mathrm{w})\end{array}$ & 150 & 100 & 150 & 200 & 125 & 110 & 111 & 105 \\
\hline $\begin{array}{l}\text { output } \\
\text { current }(\mu \mathrm{A})\end{array}$ & 18 & 12 & 7 & 5.5 & 14 & 3.5 & 5.3 & 5.3 \\
\hline
\end{tabular}

Table 6. Simulation Result Analysis-Stage output voltage Summary as 3 and 5 stages.

\begin{tabular}{l|l|l|l|l|l}
\hline $\begin{array}{l}\text { Charge pump in each } \\
\text { (N=5) stage }\end{array}$ & $\mathbf{1}^{\text {rst }}$ & $\mathbf{2}^{\text {nd }}$ & $\mathbf{3}^{\text {rd }}$ & $\mathbf{4}^{\text {th }}$ & $\mathbf{5}^{\text {th }}$ \\
\hline $\begin{array}{l}\text { Pumping voltage (using } \\
\text { inductor) }\end{array}$ & 3.5 & 5.3 & 6.3 & 8.2 & 9.1 \\
$\begin{array}{l}\text { Pumping voltage } \\
\text { (without inductor) }\end{array}$ & 3.0 & 4.1 & 5.1 & 6.1 & 7.5 \\
\hline \multicolumn{4}{|l}{} \\
\hline $\begin{array}{l}\text { Charge pump in each } \\
\text { (N=3) stage }\end{array}$ & $1^{\text {st }}$ & $2^{\text {nd }}$ & $3^{\text {rd }}$ & Vout & \\
\hline $\begin{array}{l}\text { Pumping voltage (using } \\
\text { inductor) }\end{array}$ & 3.6 & 6.3 & 8.1 & 7.26 & \\
\hline
\end{tabular}

Table 7. Result Comparison with various inductor-based charge pump.

\begin{tabular}{|c|c|c|c|c|c|c|}
\hline Parameters & 2016 & 2009 & 2017 & 2004 & This & Vork \\
\hline Process $(\mu \mathrm{m})$ & 0.18 & 0.18 & 0.18 & 0.18 & 0.18 & 0.18 \\
\hline $\operatorname{Min} \operatorname{Vin}(V)$ & 1.8 & 0.2 & 0.11 & 1.8 & 1.8 & 1.8 \\
\hline $\begin{array}{l}\text { Vout (Load } \\
\text { Resistance) }\end{array}$ & 3.4 & 1.2 & 1.5 & 6.0 & 7.3 & 6.8 \\
\hline No. of stage & 3 & 2 & 3 & 5 & 3 & 5 \\
\hline Max. Efficiency & $47 \%$ & $40.26 \%$ & $46.5 \%$ & $65 \%$ & $60 \%$ & $77 \%$ \\
\hline
\end{tabular}

\section{Conclusions}

Inductor based modified Dickson charge pump has been modeled and simulated using $0.18 \mu \mathrm{m}$ CMOS process. We applied five stage inductor-capacitors architecture to boostup efficiency and conversion ratio up to $96 \%$ at load output resistance $250 \mathrm{k} \Omega$. The efficiency was tested at various load resistance up to $1000 \mathrm{k} \Omega$ and pumping capacitors $6 \mathrm{pF}$ and $20 \mathrm{pF}$ and using $\mathrm{L}=100 \mu \mathrm{H}$. The efficiency range was observed to vary from $65 \%$ to $96 \%$. The output voltage up to $6.5 \mathrm{~V}$ to $8.5 \mathrm{~V}$ was achieved. Simulation results have been performed using 3 stage and 5 stage charge pumps. It was observed that for $\mathrm{N}=3$ stage charge pump, the efficiency 
varies $50 \%$ to $60 \%$. In contrast, $\mathrm{N}=5$ stage charge pump efficiency varies from $55 \%$ to $96 \%$ with respect to the load resistance. The Main theme of this paper, MOS resistance $\mathrm{R}_{\mathrm{on}}$ (Drain to source resistance) is designed at $20 \Omega$ and 100 $\Omega$, because of which pumping current is the regulate at each stage up to regulation level and get the higher output voltage and higher efficiency. By using the the T-Spice software in $180 \mathrm{~nm}$ CMOS technology, the simulation results of the charge pump circuit for $1.8 \mathrm{~V}$ input voltage show that the output voltage and the conversion ratio of the proposed charge pump are $7.5 \mathrm{~V}$ and $77.3 \%$, respectively. In comparison with the other charge pump circuits, the designed charge pump circuit has a higher voltage conversion ratio.

\section{Acknowledgements}

The authors would like to thank the UGC New Delhi, for providing research fellowship and financial support under the Rajiv Gandhi National Fellowship Scheme (RGNFS) in the Ph.D. Program in the growing area of VLSI Design. The authors acknowledge the support from the resources and staff at KNIT Sultanpur, UP, India.

This is an Open Access article distributed under the terms of the Creative Commons Attribution Licence

\section{References}

[1] Feng Pan and Tapan Samaddar, Charge Pump Circuit Design. McGraw-Hill Education, Electronic Engineering, ISBN-13: 9780071470452. August 2006.

[2] Charge Pumps: An Overview-CiteSeerX citeseerx.ist.psu.edu/viewdoc/download? doi=10.1.1.128.4085\&rep=rep 1

[3] J. F. Dickson, "On-chip high-voltage generation in NMOS integrated circuits using an improved voltage multiplier technique," IEEE J. Solid-state Circuits, vol. SC-11, pp. 374-378, Mar. 1976.

[4] Wu, J.T. and L.K. Chang. "MOS Charge pump for Low Voltage Operation." IEEE Journal of solid-state circuits, Vol. 33, No, \$, April 1998.

[5] A. Richelli, L. Colalongo, M. Quarantelli, Member, IEEE, M. Carmina, and Zs.M. Kovacs-Vajna, Senior Member, IEEE, “A Fully Integrated -Based 1.8-6-V step-up converter," IEEE J. Solidstate Circuits, Vol.39, No.1, January 2004.

[6] A. Richelli, L. Colalongo, Silvia Tonali, "am 0.2-1.2 V DC/DC Boost Converter for Power Harvesting Applications", IEEE Transactions On Power Electronics, Vol. 24, No. 6, PP, 1541-1546, June 2009.

[7] Tutorial on Transistor Sizing Problem \#1 (Static-CMOS-logic): https://ece.uwaterloo.ca/ mhanis/tutorials/sizing.

[8] Feng Peng, Li Yunlong, and Wu Nanjian, "A high efficiency charge pump circuit for low power applications," Journal of Semiconductors, Vol 31., No. 1, pp-015009.1-4, January 2010.

[9] G. Palumbo and D. Pappalardo, "Charge Pump Circuits: An overview on design strategies and topologies," IEEE Circuits and Systems Magazine, vol. 10, no. 1, pp. 31-45, Jan. 2010.

[10] A. K. Ong, V. I. Prodanov, M. Tarsia, Bell Laboratories, Lucent Technologies, "A Method for Reducing the Variation in "On" Resistance of a MOS Sampling Switch", ISCAS 2000 - IEEE International Symposium on Circuits and Systems, Geneva, Switzerland, May 28-31,2000.

[11] Masaki Muramatsu, and Hirotaka Koizumi, Member, IEEE, “An Experimental Result Using RF Energy Harvesting Circuit with Dickson Charge Pump.”, IEEE Conference, ICSET 6-9, Kandy, Sri Lanka, Dec 2010.

[12] Massimilliano Zucchelli, Luigi Colalongo, Anna Richelli., "Dickson charge pump using integrated inductors in complementary metal-oxide semiconductor technology," IET Power Electronics, Vol 9, pp 242-245, July.2016.

[13] H.M.P.C. Jayaweeraa, Ali Muhtaroğlua., "Design optimization of a fully integrated charge-pump with LC tank oscillator for ultra-low voltage energy harvesting", Microelectronics Journal 59 (2017) 3339. Jan 2107.

[14] H.M.P.C. Jayaweeraa, Ali Muhtaroğlua, "Model based optimization of integrated low voltage DC-DC Converter for Energy Harvesting Applications.” Journal of Physics Conference series 773-2016.

[15] Muhammad Bilal Saif, Yingjie Xu, Klaus Hofmann, "Comparison of Charge Pump and Boost Circuit for high voltage and Low power voltage conversions." 58th International Symposium ELMAR2016, 12-14 September 2016, Zadar, Croatia.

[16] Anna Richelli, Simone Comensoli, and Zsolt M. Kovács, "A DC/DC Boosting Technique and Power Management for Ultra Low-Voltage Energy Harvesting Applications", IEEE Transactions On Industrial Electronics, Vol. 59, No. 6, pp 2701-2707, June 2012.

[17] R. Jacob Baker, Harry W. Li and David E. Boyce, CMOS Circuit Design and Layout, and Simulation, Department of Electrical Engineering, Microelectronics Research Centre the University of Idaho IEEE Press Series on Microelectronic Systems, ISBN $0 \cdot 7803 \cdot 3416 \cdot 7,1998$

[18] T. Tanzawa, "A switch-resistance-aware Dickson charge pump model for optimizing clock frequency," IEEE Transactions on Circuits and System II: Express Briefs, vol. 58, no. 6, pp. 336-340, Jun. 2011.

[19] Yongbo Liua, b, Zhengyong Zhua, Huilong Zhua, "Charge pumps, test technique using CMOS ring oscillator on the leakage issue", Microelectronics Journal 68 (2017) 40-43.

[20] Vladimir Stojanovic and Vojin G. "Comparative Analysis of Master- Slave Latches and Flip-Flops for High-Performance and Low-Power Systems, " IEEE Journal of Solid-State Circuits, Vol. 34, No. 4, April 1999.

[21] G. Palumbo, D. Pappalardo, M. Gaibotti, "Charge Pump CircuitsPower Consumption optimization," IEEE Trans. Circuits and Systems I: Fundamental Theory and Applications, vol. 49, no. 11, pp. 1535-1542, Nov. 2002.

[22] Hung Peng, Nghia Tang, Young Yang, Member, IEEE, "CMOS Start-up Charge Pump With Body Bias and Backward Control for Energy Harvesting Step-Up Converters", IEEE Transactions On Circuits And Systems I: Regular Papers, Vol. 61, No. 6, pp 16181628, June 2014.

[23] T. Tanzawa, "On two-phase switched-capacitor multipliers with the minimum circuit area," IEEE Transactions on Circuits and Systems I: Regular Papers, vol. 57, no. 10, pp. 2602-2608, Oct. 2010.

[24] Y. Moisiadisa, I Bourasc, and A. Arapoyanni, "Charge Pump Circuits for Low-voltage Applications," Taylor and Francis VLSI Design, Vol. 15 (1), pp. 477-483, 2002. 